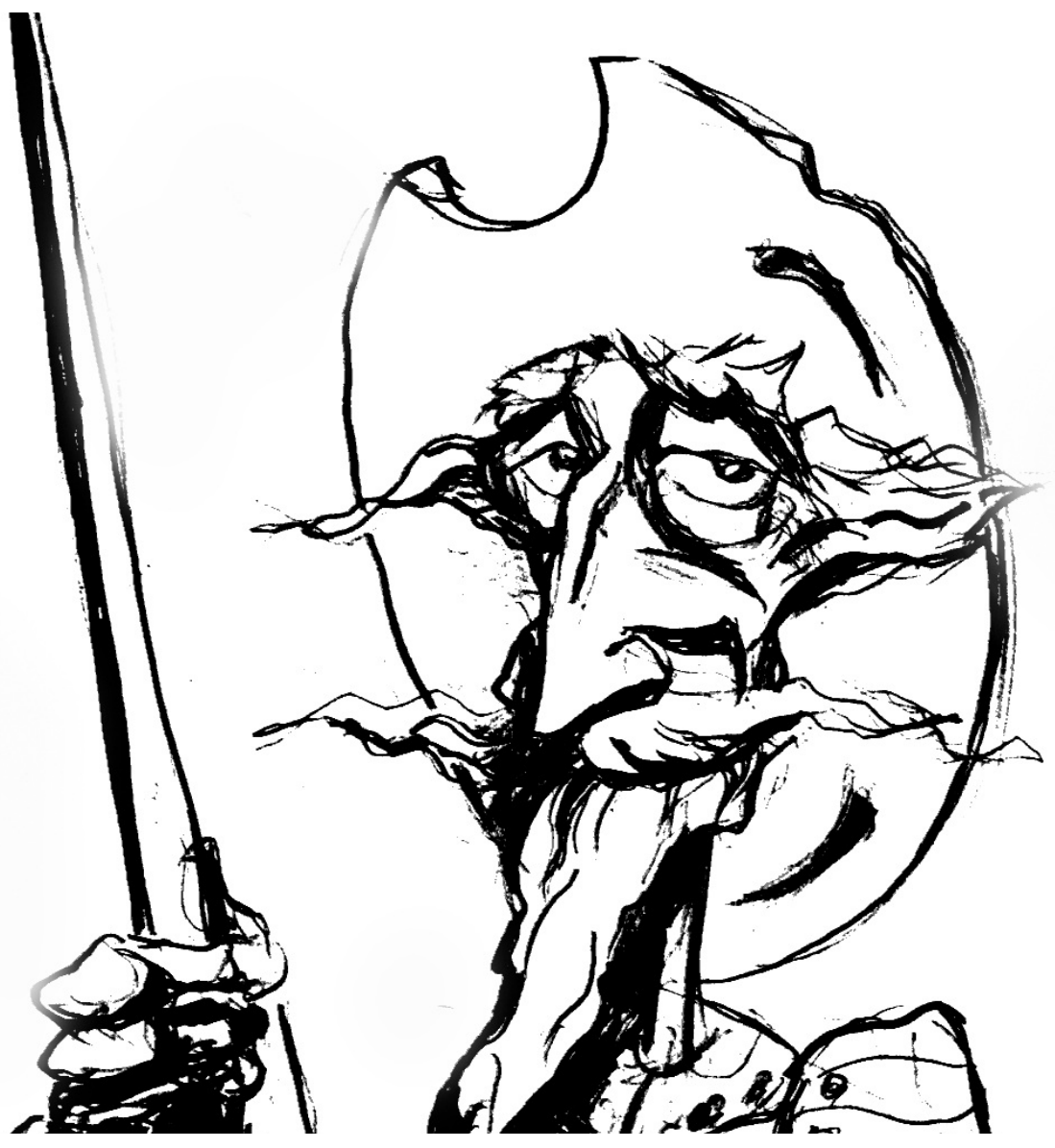

El discurso nacionalsocialista en la Argentina frente a la "infiltración nazi"

[Germán Friedmann] 



\title{
El discurso nacionalsocialista en la Argentina frente a la “infiltración nazi"*
}

\author{
National Socialist Discourse Against "Nazi infiltration" in Argentina
}

\author{
GERMÁN FRIEDMANN
}

\section{Resumen}

Desde mediados de la década de 1930 prosperaron diversos informes sobre una infiltración nacionalsocialista en la Argentina, preparada para un eventual asalto al continente sudamericano. En su origen y difusión se destacó la labor propagandística de militantes de distintas organizaciones germanoparlantes que conformaron un variopinto movimiento antifascista local. El artículo centra su atención en los discursos e interpretaciones de los nacionalsocialistas locales, para quienes las denuncias sobre una omnipresente "amenaza nazi" respondían a una "propaganda de difamación" de agencias de noticias internacionales que encubría lo que consideraban como la verdadera amenaza de la “infiltración judía” y el "imperialismo anglo-yanqui".

\section{Palabras clave}

Nacionalsocialismo; antifascism; germano-argentinos; antisemitismo; antiimperialismo

\begin{abstract}
From the mid-1930s diverse reports alerting about a National Socialist infiltration into Argentine territory, prepared for an eventual assault on the South American continent, have prospered. The propagandistic labor of militants from different German-speaking organizations that made up a motley local antifascist movement played a large part in their origin and dissemination. This article focuses on the discourse and interpretations of local National Socialists, for whom the denunciations of an omnipresent "Nazi threat" were part of a "defamation propaganda" of international news agencies that covered up what they considered to be the real threat of the "Jewish infiltration" and "Anglo-Yankee imperialism".
\end{abstract}

\section{Key Words}

National Socialism; anti-fascism; german-argentine; anti-Semitism; anti-imperialism

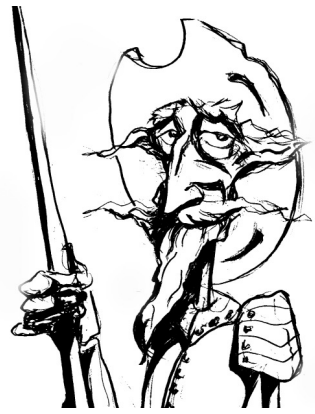

Recibido con pedido de publicación el 27 de julio de 2019

Aceptado para su publicación el 4 de octubre de 2019

Versión definitiva recibida el 21 noviembre de 2019

Germán Friedmann, Universidad de Buenos Aires, Consejo Nacional de Investigaciones Científicas y Técnicas, Buenos Aires, Argentina; e-mail: gerfriedmann@yahoo.com.ar

\footnotetext{
* Agradezco las aportaciones de los réferis anónimos de Revista Prohistoria

Esta obra se publica bajo licencia Creative Commons. Atribución-NoComercial-CompartirIgual $(\mathrm{cc})$ EY-NC-sA 4.0 Internacional
}

Friedmann, Germán “El discurso nacionalsocialista en la Argentina frente a la 'infiltración nazi'”, Prohistoria, Año XXII, núm. 32, dic. 2019, pp. 127-154 
Desde mediados de la década de 1930 prosperaron diversos informes sobre una infiltración nacionalsocialista en la Argentina, preparada para un eventual asalto al continente sudamericano. En su origen y difusión se destacó la labor propagandística de militantes de distintas organizaciones germanoparlantes que conformaron un variopinto movimiento antifascista local.

El artículo centra su atención en los discursos e interpretaciones de los nacionalsocialistas locales, para quienes las denuncias sobre una omnipresente "amenaza nazi" respondían a una "propaganda de difamación" de agencias de noticias internacionales que encubría lo que consideraban como la verdadera amenaza de la "infiltración judía" y el "imperialismo anglo-yanqui". ${ }^{1}$

Este trabajo tiene una organización temática y cronológica, consta de cinco partes y una sección que reúne las conclusiones. Los dos apartados iniciales abordan la segunda mitad de la década de 1930. El primero de ellos da cuenta de las denuncias sobre la supuesta "infiltración nazi" que, impulsadas inicialmente por militantes antihitleristas de habla alemana, alcanzaron luego una importante repercusión en la opinión pública local. El segundo presenta las diversas repercusiones internacionales de aquellas acusaciones así como las primeras respuestas a las mismas elaboradas por los nacionalsocialistas.

Los tres apartados siguientes centran su atención en los inicios de la década de 1940, y presentan la postura de los partidarios locales del régimen de Hitler, quienes, ante la extendida alarma de una potencial amenaza "amenaza nazi" atribuyeron el verdadero peligro a las maniobras de una "plutocracia judía" que impulsaría por igual al imperialismo británico y a los intentos de avanzada norteamericanos sobre el continente. Además, muestra cómo aquel discurso logró enlazarse con un conjunto de ideas que contaban con una creciente aceptación en una parte considerable del ámbito político nacional. A continuación se exponen las consideraciones finales.

No obstante la indudable relevancia del tema, las investigaciones sobre las actividades y los discursos de quienes se sentían identificados con el nacionalsocialismo de la Argentina han sido generalmente relegadas por la historiografía académica. Así, esta investigación, focalizada en el discurso de los partidarios locales del tercer Reich pretende aportar algunas respuestas a una serie de cuestiones que hasta el momento fueron escasamente exploradas por la bibliografía existente.

\footnotetext{
${ }^{1}$ Muchas fuentes utilizadas en este trabajo fueron publicadas originalmente en idioma alemán. Son reproducidas aquí en la traducción al castellano del autor.
} 


\section{Las "actividades disolventes de los agentes de la internacional parda"}

Hacia mediados de la década de 1930 y comienzos de la siguiente muchas de las disputas internas del ámbito político argentino fueron interpretadas bajo la óptica de los conflictos mundiales contemporáneos. En ese marco surgieron numerosas denuncias que alertaban sobre la presencia de una "quinta columna" nacionalsocialista en el país que estaría preparada para iniciar acciones militares en el continente. Los simpatizantes del régimen de Hitler consideraban que aquellos informes formaban parte de una intensa campaña de desprestigio encabezada por diversas agencias de noticias internacionales contra el nuevo gobierno del Reich. Más allá de las teorías conspirativas tan proclives a ser aceptadas por militantes de variadas agrupaciones políticas, entre ellas la nacionalsocialista, lo cierto es que en la propagación de las más efectistas exageraciones sobre una supuesta penetración nacionalsocialista jugó un papel relevante la labor propagandística de activistas de distintas organizaciones antihitleristas de habla alemana radicadas en la Argentina.

La línea editorial del diario Argentinisches Tageblatt se opuso al partido nacionalsocialista antes de que este gobernara Alemania y desde mediados de 1933 condenó abiertamente la alineación al tercer Reich de diversas instituciones germano-parlantes establecidas en la Argentina. ${ }^{2}$ También el periódico Die Schwarze Front, perteneciente a un grupo de disidentes nacionalsocialistas enfrentados a Hitler, denunció el copamiento de diferentes instituciones de la colectividad alemana por parte de una extensa "red parda". ${ }^{3}$ En un principio la opinión pública nacional permaneció indiferente ante lo que percibía como disputas internas de aquella comunidad. Esta postura varió sensiblemente a partir de 1937 cuando comenzaron a elaborarse frecuentes informes sobre los "planes sudamericanos" del nacionalsocialismo que involucrarían a un conjunto de personas más amplio. ${ }^{4}$

Aquellas denuncias iniciadas en publicaciones de idioma alemán alcanzaron luego una amplia resonancia en la prensa de alcance masivo y en ella también jugó un papel significativo la labor de diversos integrantes de instituciones de habla alemana opositoras a Hitler. Una serie de notas publicadas durante el mes de abril de 1938 en el diario Crítica -el de mayor tirada nacional- sobre las "actividades disolventes de los agentes de la

\footnotetext{
${ }^{2}$ Hacia 1925 el Argentinisches Tageblatt editaba cerca de 20.000 ejemplares, diez años más tarde trepó a los 28.000 y se ha estimado que hacia el final de la Segunda Guerra Mundial alcanzó entre los 40.000 y 50.000 números (Groth, 1996; Schoepp, 1996).

${ }^{3}$ El título completo de la publicación era Die Schwarze Front. Kampfblatt für Südamerika (El Frente Negro. Diario de Combate para Sudamérica) y su primer número editó 3.000 ejemplares. Sobre la agrupación Die Schwarze Front ver Friedmann, 2015.

${ }^{4}$ Argentinisches Tageblatt (4 de septiembre de 1937).
} 
internacional parda" tuvo un gran impacto público. ${ }^{5} \mathrm{Su}$ autor fue el periodista alemán Heinrich Grönewald, quien además de desempeñarse como corresponsal de aquél periódico, ocupaba un lugar destacado en la agrupación antinazi Das Andere Deutschland. ${ }^{6}$ El eco en la prensa argentina fue tan grande que en una nota del Argentinisches Tageblatt titulada "Desde La Razón hasta Crítica. Un frente de unidad contra la infiltración nazi", el mismo Grönewald se enorgullecía de las repercusiones alcanzadas por sus artículos que habían abarcado el amplio abanico ideológico representado por los periódicos mencionados. ${ }^{7}$ En efecto, independientemente de los diversos matices y de la disparidad de opiniones de las líneas editoriales frente al fenómeno nacionalsocialista, las sospechas de un intento de violación a la soberanía argentina estaban presente en diferentes grados en numerosas publicaciones de alcance nacional.

Aquel temor se vio incrementado por la incorporación de la región de los Sudetes al Reich y por la realización del denominado Anschluss austríaco, ambos sustentados en la voluntad de unificar al "pueblo alemán", independientemente de dónde este se encontrase (Bauer, 2017). Esto contribuyó a la adhesión, al menos parcial, de vastos sectores a un conjunto de políticas restrictivas implementadas por el gobierno brasileño que fueron percibidas como legítimas medidas defensivas contra un intento nacionalsocialista de invadir al país vecino para proyectarse desde allí al resto del continente. ${ }^{8}$ Estas leyes fueron apoyadas por el diario Crítica que, bajo el título de "El peligro nazi en América," publicó un artículo de João Fernandes Café Filho, por entonces exiliado en la Argentina. ${ }^{9}$ No obstante aquella condición, quien quince años más tarde se convertiría en el primer presidente protestante del Brasil elogiaba aquellas disposiciones que restringían las actividades políticas extranjeras porque, en su opinión, encabezaban una "campaña contra el nazismo". Café Filho instaba además al gobierno argentino a prestar particular atención porque "combatidos los nazis en Brasil con la eficacia y la energía que impone la defensa de la

\footnotetext{
5 "Las escuelas nazis de Entre Ríos funcionan por orden de Hitler" (20 de abril de 1938), Crítica, p. 5.

6 Sobre Das Andere Deutschland ver Friedmann, 2010.

${ }^{7}$ Grönewald, Heinrich (7 de abril de 1938). "Von Razón bis Crítica. Ein Einheitsfront gegen Naziinfiltration", Argentinisches Tageblatt, p. 3.

8 Una fuerte campaña nacionalizadora del Estado Novo reprimió con firmeza la autonomía cultural de los ciudadanos de "origen extranjero," a quienes se exigió una adhesión manifiesta a la patria brasileña. Así, se limitaron las actividades de diversas instituciones comunitarias, entre ellas las alemanas y particularmente las vinculadas al partido nacionalsocialista local, que sería finalmente prohibido en abril de 1938 (Seyferth, 1999).

9 João Fernandes Café Filho (Natal, 1899- Rio de Janeiro, 1970) fue un periodista brasileño que en 1930 se unió al movimiento político de Getulio Vargas. Tras la clausura del Congreso en 1937, abandonó su banca de diputado y se exilió en la Argentina. Retornado a su país natal, fue elegido vicepresidente en 1950 y, luego del suicidio de Vargas en 1954, asumió la presidencia hasta noviembre del año siguiente.
} 
soberanía de la nación”, los “dirigentes de la campaña nacionalsocialista en mi país" pasarán hacia "este lado de la frontera y aquí instalarán su cuartel general en América". ${ }^{10}$ También Fastrás, autodefinido como "el diario de los radicales que apoyan al doctor Ortiz", calificaba a "los planes del nazismo en Brasil como un peligro para América" y ponderaba la actitud del gobierno de Vargas porque, expresaba, "ni allá ni aquí puede tolerarse la existencia y actividades de 'minorías' raciales contrarias al interés nacional". ${ }^{11}$ Del mismo modo, el Argentinisches Tageblatt exigía que todos los gobiernos sudamericanos y particularmente el argentino implementaran disposiciones semejantes. Así, ante lo que veían como una "amenaza nazi", diversos sectores del antifascismo local no solo defendían, sino que además tomaban aquellas disposiciones represivas del Estado Novo como un modelo a seguir.

En ese contexto el legislador socialista Enrique Dickmann denunció, en la Cámara de Diputados de la Nación, una intensa y sigilosa campaña que buscaba intensificar la "influencia del Reich" sobre millones de alemanes y sus descendientes, y presentó un proyecto de resolución para investigar las "actividades ilícitas" presuntamente implementadas por "organizaciones económicas, políticas y culturales extranjeras radicadas en el país". Una disposición similar fue impulsada en la misma sesión por el radical Raúl Damonte Taborda, quien se centró en las asociaciones de "ideología nacionalsocialista", cuya doctrina, indicaba, pretendía "infiltrarse en nuestra colectividad" para culminar el "viejo sueño alemán" de alcanzar "la hegemonía mundial". ${ }^{12}$

La publicación Der Deutsche in Argentinien, editada por el Frente Alemán del Trabajo en la Argentina, exhibió una de las primeras reacciones de los germano-parlantes afines al gobierno de Hitler ante las denuncias sobre las supuestas actividades subversivas llevadas a cabo por los nacionalsocialistas. ${ }^{13}$ En sus páginas alertaba sobre "una prensa de difamación que permanentemente difunde mentiras contra Alemania y contra nosotros," e incluso, señalaba, "un parlamentario, el señor Dickmann", se "atrevió a repetir las mismas mentiras ante el foro de los representantes del pueblo argentino". Sin embargo, llamaba a sus lectores a no perder la calma porque "lo que más

10 Café Filho, João (22 de abril de 1938). "El peligro nazi en América”, Crítica, p. 9.

11 "El nazismo conspira abiertamente contra nuestra nacionalidad" (25 de marzo de 1938), Fastrás, p. 1.

${ }^{12}$ Congreso nacional, Cámara de Diputados, Diario de Sesiones, 18 de mayo de 1938, pp. 213225.

${ }^{13}$ El Frente Alemán del Trabajo (Deutsche Arbeitsfront) de la Argentina fue la organización nacionalsocialista que contó con la mayor cantidad de afiliados (cerca de 10.000). Su publicación, Der Deutsche in Argentinien (El alemán en la Argentina), editada en Buenos Aires entre 1934 y 1945, fue la sucesora de Der DHV am La Plata. 
nos tranquiliza es que no son argentinos quienes nos difaman, sino extranjeros: judíos y compañeros de los judíos (Judengenossen)". ${ }^{14}$

\section{Invasión nazi contra infiltración judía}

Las prácticas ilícitas de los nacionalsocialistas adquirieron aún mayor protagonismo con el denominado "affaire de la Patagonia", provocado por un presunto ardid del gobierno del Reich para apoderarse del sur argentino. Desde entonces el "peligro alemán" y el "espionaje nazi" fueron temas persistentes en la política interna (Newton, 1992: 194-214). El escándalo patagónico se originó a partir de un conjunto de pruebas adulteradas que fueron proporcionadas a las autoridades nacionales por Heinrich Jürges, una persona que había alcanzado cierta relevancia en el ambiente de habla alemana local por su desempeño como vicedirector del Schwarze Front sudamericano. ${ }^{15}$ Jürges elaboró aquella falsificación en el estudio fotográfico de la retratista Annemarie Heinrich, quien luego ocuparía un lugar destacado en el mundo artístico argentino. ${ }^{16}$

Cuando las redacciones del Argentinisches Tageblatt y del vespertino Noticias Gráficas conocieron el contenido de aquella documentación incrementaron la campaña que habían emprendido previamente contra las actividades nacionalsocialistas. En este aspecto, el Argentinisches Tageblatt denunció las "maniobras nazis" tendientes a la separación de la Patagonia del territorio argentino e indicó que el principal objetivo de la propaganda secesionista era allanar el camino a una invasión que, como en Checoslovaquia, podría tener el apoyo de la cuantiosa y "nazificada" colonia alemana local. ${ }^{17}$ En el mismo sentido se pronunció el presidente de la Junta Central Pro Autonomía y Fomento de los Territorios Nacionales, Alberto Grassi, al considerar que la campaña nacionalsocialista en la Patagonia perseguía la finalidad de crear "los 'Estados Unidos del Sur' bajo control alemán". ${ }^{18}$ Por su parte, el diario La Prensa se sumó al reiterado reclamo del Argentinisches Tageblatt que exigía la urgente expulsión del país de los nacionalsocialistas y el periódico La Vanguardia alertó sobre la posibilidad cierta de que el país se transformara en una colonia alemana. ${ }^{19}$ También La Nación, El Mundo y La Razón denunciaron las

\footnotetext{
14 "Die Deutsche in Argentinien" (julio de 1938), Der Deutsche in Argentinien, p. 295. En el lenguaje nacionalsocialista Judengenosse era una denominación denigratoria para quienes eran acusados de colaborar con los judíos (Schmitz-Berning, 2007: 329-330).

${ }^{15}$ Sobre Jürges ver Rout y Bratzel, 1984.

${ }^{16}$ Bergadá Mugica, Justo (1939). Infiltración?-¿Espionaje? Informe "in voce" del Dr. Justo Bergadá Mugica en el proceso seguido al Señor Alfredo Müller referente a la infiltración Nazi en la Patagonia, p. 15.

${ }_{17}$ Argentinisches Tageblatt (1 de febrero de 1939), p. 1.

${ }^{18}$ Argentinisches Tageblatt (9 de febrero de 1939)

${ }^{19}$ La Prensa, 3 de abril de 1939; y La Vanguardia, 10 de abril de 1939.
} 
aspiraciones alemanas sobre el continente americano en general y sobre la Argentina en particular (Friedmann, 2010: 83-86).

Además de ser reflejados por los medios locales más importantes, los informes sobre el "affaire de la Patagonia" tuvieron igualmente una amplia repercusión internacional. Las noticias se publicaron en The Washington Post, lo que incitó al Argentinisches Tageblatt a proclamar la composición de un "frente americano contra los abusos nazis". ${ }^{20}$ En este sentido, David Efron, por entonces profesor de Cultura Americana en el Sarah Lawrence College del estado de Nueva York, anunció ante la prensa norteamericana que los nacionalsocialistas habían ofrecido "armas y municiones para una revolución en la Patagonia." Como lo hiciera el Argentinisches Tageblatt también Efron (estrechamente vinculado al Comité Contra el Racismo y el Antisemitismo), ${ }^{21}$ manifestó que el tercer Reich anhelaba la separación del sur argentino "por los mismos motivos que había reivindicado la autonomía de la región de los Sudetes". ${ }^{22}$ Cabe destacar que para una parte importante de la opinión pública de los Estados Unidos era verosímil que al sur de sus fronteras existiera una confabulación que incluiría no solo a los funcionarios de las embajadas y consulados, sino además a una población germanoparlante que, percibida como alineada al sistema nacionalsocialista, seguiría sin mayores cuestionamientos las órdenes del Tercer Reich. ${ }^{23}$ El mismo Efron denunció la existencia de una "santa alianza" fascista que buscaba infiltrar América Latina, tesis que sostuvo luego ante la comisión de relaciones exteriores del senado estadounidense, donde encontró un clima más que propicio para su aceptación (Efron, 1939). Hay que tener en cuenta que más allá de las diversas operaciones de inteligencia y propaganda impulsadas por diversos organismos, muchos dirigentes norteamericanos y, entre ellos, algunos miembros del gobierno de Roosevelt estaban convencidos de que los nacionalsocialistas tenían un "terreno fértil" en América Latina. De hecho, en una atmósfera crecientemente signada por el "terror nazi", cerca de 4.000 alemanes radicados en los países de la cuenca del Caribe fueron deportados de sus lugares de residencia y confinados en campos de concentración establecidos en los Estados Unidos (Friedman, 2003).

A diferencia de lo sucedido con el Argentinisches Tageblatt, la línea editorial del Deutsche La Plata Zeitung -el otro periódico en idioma alemán de gran tirada

\footnotetext{
${ }^{20}$ Argentinisches Tageblatt (9 de abril de 1939).

21 Sobre esta agrupación ver Senkman, 1991.

22 "Naziangebot: Waffen und Munition für eine Revolution in Patagonien" (8 de abril de 1939), Argentinisches Tageblatt, p. 3.

${ }^{23}$ Aunque en sus informes las autoridades norteamericanas mostraron un cuadro relativamente meticuloso de la composición y las actividades de las organizaciones alemanas en América Latina, sobreestimaron no obstante sus capacidades para instrumentalizar a la población germanoparlante hacia los objetivos del partido nacionalsocialista (Lübke, 2008).
} 
de la Argentina- tuvo una posición favorable al régimen de Hitler. ${ }^{24} \mathrm{Su}$ semanario, La Plata Post, refutó fuertemente a los medios que habían publicitado la existencia de un proyecto nacionalsocialista de anexión de la Patagonia sin chequear previamente su autenticidad y dio a conocer el "prontuario de Jürges," a quien responsabilizaba por aquella "falsa propaganda". ${ }^{25}$ El Deutsche La Plata Zeitung caracterizó de "pseudoalemanes" y "Semigranten" (juego de palabras entre semitas y emigrantes) a los integrantes de Das Andere Deutschland quienes, señalaba, aunque jugaban el papel de "verdaderos alemanes" ante la opinión pública, no eran más que un grupo de judíos y fugitivos "traidores a la patria" que mentían descaradamente para perjudicar a los "compañeros del pueblo" (Volksgenossen) nacionalsocialistas de la Argentina. ${ }^{26}$

De igual forma Der Trommler (el boletín oficial del partido nacionalsocialista de la Argentina) denunció la existencia de una "campaña de calumnias antialemana" basada en un material apócrifo suministrado por un "ex convicto, falsificador de documentos, estafador y bígamo". ${ }^{27}$ Esta semblanza de Heinrich Jürges nada tenía que envidiarle a la de Enrique Dickmann, presentado por Der Trommler como un "judío nacido en Odesa y naturalizado argentino" que pretendía "envenenar" las relaciones germano-argentinas porque, debido a su "pertenencia racial," odiaba en forma "desenfrenada" a los alemanes. “¿En nombre de quién habla usted, señor Dickmann?”, se preguntaba Der Trommler, "¿habla en nombre del pueblo argentino o utiliza su banca de representante de una nación que es amiga del imperio alemán desde hace 129 años y que generosamente le abrió sus puertas, para asumir el papel de vocero del judaísmo internacional?" 28

\footnotetext{
${ }^{24}$ Fundado en 1863, el Deutsche La Plata Zeitung fue el primer periódico en idioma alemán establecido en la Argentina. Estuvo estrechamente ligado al Reich bismarckiano y fue un ferviente adversario del estado de Weimar, al que veía alejado del "verdadero espíritu alemán." Desde 1933 se acercó al nacionalsocialismo y contó con el sostén económico del gobierno alemán. Entre 1925 y 1945 mantuvo su tirada en alrededor de 40.000 ejemplares (Laberenz, 2006: 63; Ismar, 2006: 45-104).

25 “Ein übliges Lügengewebe wird immer durchsichtiger!” (5 de abril de 1939), La Plata Post, p.1.

26 "Pseudodeutsche hetzen mit" (19 de abril de 1939), Deutsche La Plata Zeitung, p. 5. La palabra Volksgenosse se utilizó durante el siglo XIX como sinónimo de Landsmann (compatriota). Entre los nacionalsocialistas el término designaba a los miembros de una "comunidad de la sangre" (Schmitz-Berning, 2007: 660).

27 Der Trommler. Mitteilungsblatt für die Nationalsozialistische Bewegung des Deutschen in Argentinien (El Tambor. Boletín informativo del movimiento nacionalsocialista de los alemanes de la Argentina) era la publicación oficial del Landesgruppe Argentinien (Grupo Territorial Argentina) de la Auslandsorganisation der National sozialistische Deutsche Arbeiterpartei (Organización Exterior del Partido Nacionalsocialista Obrero Alemán). Editada en Buenos Aires entre 1934 y 1945, llegó a imprimir entre 4.000 y 6.000 ejemplares.

28 "Nicht mehr ganz originell. In wessen Namen sprechen Sie, Herr Dickmann?" (20 de junio de 1939), Der Trommler, pp. 59 y ss.
} 
Aquel ataque directo contra el dirigente socialista respondía a que en junio de 1939 Dickmann -quien como Efron, integraba el Comité Contra el Racismo y el Antisemitismo- había ampliado en la Cámara de Diputados las denuncias que formulara un año atrás, señalando que los nacionalsocialistas no se limitaban ya a operar dentro de la comunidad alemana, sino que también lo hacían sobre "elementos ultra-reaccionarios de la población" que conspiraban contra la soberanía nacional. ${ }^{29}$

El "escándalo de la Patagonia" tuvo también repercusiones en Alemania. Allí, el periódico National Zeitung manifestó que los germano-parlantes residentes en América Latina eran víctimas de "encarnizadas persecuciones" que podrían ser fácilmente detenidas si se viera con claridad la "verdadera intención" perseguida por la "fábula de la "infiltración nazi". 30 Aquella "floreciente tontería", que habría sido difundida por la prensa sensacionalista norteamericana para legitimar la "protección de los Estados Unidos en el caso de una 'invasión totalitaria", era motorizada, según el corresponsal local del National Zeitung, por "un evidente complot continental del judaísmo." Así como Monroe había declamado una "América para los americanos", ahora Roosevelt, continuaba la nota, bregaba por una "América para los buenos vecinos", pero con ello pretendía que el continente entero quedara "en manos de los comerciantes judíos", de quienes era su "portavoz oficial". Las "leyendas patagónicas," sostenía el diario alemán, formaban parte de una "danza de agitación judaico-marxista," cuyo "padre espiritual era un judío de nacionalidad argentina, el profesor David Efron", a quien definía como un "consejero íntimo de los dirigentes de su misma raza en las cuestiones de la Alianza Panamericana, según la receta del secretario de estado Cordell Hull". Pero las verdaderas intenciones de aquella campaña difamatoria se evidenciaban para el National Zeitung en las palabras de Enrique Dickmann que ante la amenaza de perder la Patagonia habría planteado como solución su rápido poblamiento, brindando "asilo a todos los perseguidos por el odio de razas totalitario". Así, clamaba el periódico editado en Essen, "la quimera de la "invasión nazi" habría sido urdida para que "la Argentina ofreciera la Patagonia a los judíos como tierra prometida". ${ }^{31}$

En el mismo sentido Der Trommler aseveraba que la "verdadera infiltración de elementos extraños" en la Argentina debía buscarse "donde

\footnotetext{
${ }^{29}$ Congreso nacional, Cámara de Diputados, Diario de Sesiones, 9 de junio de 1939, p. 474. Sobre los debates parlamentarios en torno a la "infiltración nazi" ver Friedmann, 2009.

${ }^{30}$ El National Zeitung fue editado entre 1930 y 1945. Hacia 1939 tenía una tirada cercana a los 170.000 ejemplares. Börsenverein der Deutschen Buchhändler (Asociación de libreros alemanes) (comp.) (1939), Sperlings Zeitschriften- und Zeitungsadreßbuch. Handbuch der deutschen Presse, núm. 61, Leipzig, p. 428.

31 "Patagonische Legenden. Amerika den Juden. Die Hintergründe der Dokumentenfälschung" (6 de mayo 1939), en National Zeitung, Essen. La nota era autoría del corresponsal del periódico en Sudamérica, MCK, quien también escribía en Der Trommler.
} 
realmente se lleva a cabo y no donde los infiltrados la señalan con el dedo". La publicación nacionalsocialista advertía sobre la emigración de quienes "descubrieron América como la nueva tierra prometida" y utilizaban el "camuflaje con nombres españoles" para blanquear sus antecedentes a los ojos de potenciales socios o clientes. Así describía como, mediante un "proceso completamente inofensivo de naturaleza puramente jurídica", un judío llamado Schejtman había entrado al palacio de justicia, retornando al poco tiempo con el apellido "Cortés", hecho al que Der Trommler atribuía cierta justicia poética, pues "¿no tiene derecho un Schejtman a tomar el nombre robado de Cortés si, después de todo, no viene al país como un conquistador tramposo?" 32

\section{El zarpazo del imperialismo yanqui}

La investigación sobre la infiltración nacionalsocialista tuvo durante 1940 un paréntesis legislativo. No obstante, las denuncias fuera del parlamento siguieron siendo numerosas y era cada vez más considerable el conjunto de personas que creía en la posibilidad cierta de la amenaza una "quinta columna" nacionalsocialista que estaría preparada para iniciar acciones militares en América Latina. Nuevamente fue Heinrich Grönewald quien impulsó aquellas acusaciones tanto desde el Argentinisches Tageblatt como desde Informaciones para la prensa sudamericana, un boletín editado en castellano por Das Andere Deutschland. ${ }^{33}$ En esta oportunidad centró sus informes en las acciones emprendidas por presuntos agentes del tercer Reich dentro de la comunidad alemana del territorio nacional de Misiones, donde consideraba que podía conformarse un potencial centro de agitación. ${ }^{34}$ Estas afirmaciones tuvieron una amplia divulgación en un momento en el que la prensa argentina ya estaba plagada de notas y artículos referidos a una "invasión nazi".

Aquella situación impactó fuertemente en vastos sectores de germanoparlantes radicados en la Argentina que creían presenciar una creciente oleada antialemana. Este sentimiento ya estaba presente en muchos alemanes cuando el 15 de mayo de 1939 el Poder Ejecutivo dictó el decreto número 31.321 que limitaba las actividades políticas de los extranjeros y establecía la "argentinización" de todas sus asociaciones para "asegurar la

\footnotetext{
32 "Infiltration. Kein leerer Wahn! Wie der Schejtman zum Porteño wird" (5 de octubre de 1940), Der Trommler, p. 27.

${ }^{33}$ Grönewald dirigió aquel boletín que fue enviado gratuitamente a agencias de prensa, diarios, revistas y estaciones de radio del continente. Según Das Andere Deutschland, Informaciones para la prensa sudamericana habría llegado a alrededor de 6.000 publicaciones de países de habla hispana y portuguesa. "Das Andere Deutschland und die antifaschistische deutsche Bewegung in Südamerika" (febrero de 1943), Das Andere Deutschland, p. 18.

${ }^{34}$ Grönewald, Heinrich (28 de julio de 1940). "Nazi-Verschwörung in Eldorado", Argentinisches Tageblatt, p. 6.
} 
integridad espiritual de la nación". ${ }^{35}$ Esta disposición implicó la rápida prohibición de distintas organizaciones dependientes del partido nacionalsocialista que, si bien burlaron aquella instrucción acudiendo a diversas maniobras, desde entonces adoptaron un perfil mucho más discreto para evitar una excesiva exposición en la opinión pública argentina. ${ }^{36}$ Sin embargo, sus integrantes no fueron los únicos alemanes afectados por aquella decisión gubernamental. De hecho, los militantes antinazis de Das Andere Deutschland entendían que las noticias que "desde la izquierda hasta la derecha colmaban la prensa argentina" habían contribuido claramente a que "hoy alemán sea un insulto" así como a que "en numerosos lugares los alemanes fueran interrogados y detenidos" y a que "por todas partes la atención de la policía estuviera dirigida hacia ellos". ${ }^{37}$

Ante ese escenario percibido como de renovado "odio hacia los alemanes", la publicación oficial del partido nacionalsocialista de la Argentina denunció una "incesante campaña de difamación impulsada por los desperados internacionales de la tribu de Abraham" e indicó que las "grotescas marionetas de la eterna germanofobia" contaban con un extenso hilo que se extendía "hasta la tierra del Tío Sam". ${ }^{38}$ Der Trommler subrayaba que las "fuerzas anónimas que siempre aparecen en escena cuando están en juego los grandes negocios del capital financiero internacional" habían vuelto a colocar a la "invasión nazi" en el centro de la escena. Denunciaba además que aquellos "focos de peligro" se buscaban siempre de manera premeditada en "territorios lejanos" porque pretendían impactar en la población de la capital argentina que, escasamente "familiarizada con las verdaderas condiciones de las distantes partes del país," podía creer "cualquier mentira por más tonta y temeraria que sea". Incluso, indicaba la publicación nacionalsocialista, los grandes diarios "reconocidos como parte de la prensa seria, no se avergonzaban de admitir en sus columnas las torpezas más escandalosas". ${ }^{39}$

Cuando en el viejo continente el avance de las tropas alemanas parecía irrefrenable Der Trommler observaba un renovado escenario mundial con una

\footnotetext{
${ }_{35}$ Boletín oficial, 31 de mayo de 1939, pp. 6.725.

36 Tras su disolución oficial el Nationalsozialistische Deutsche Arbeiterpartei Landesgruppe Argentinien (Grupo Territorial Argentina del Partido Nacionalsocialista Obrero Alemán) continuó funcionando con el nombre de Bund Deutscher Wohlfahrts-und Kulturgemeinschaften (Federación de Círculos Alemanes de Beneficencia y Cultura). Existen distintas opiniones sobre la importancia de esta asociación. Mientras que algunos indicaron que tuvo una influencia limitada sobre la comunidad alemana, otros señalaron que el decreto de mayo de 1939 solo ocasionó el cambio de nombre, pero su actividad no habría experimentado prácticamente ninguna transformación. Newton, 1992: 213-214; Lütge, 1981: 298-299.

37 “Was ist mit Patagonien?" (1 de marzo de 1939), Das Andere Deutschland, p. 3.

38 "Dem Dünkirchen entgegen. Schattenspiele der Deutschlandhetze" (5 de octubre de 1940), Der Trommler, pp. 19-20.

${ }^{39}$ Dr. A, “Deutschenhetze wieder aktuell” (5 de octubre de 1940), Der Trommler, p. 32.
} 
Europa consolidada bajo el "liderazgo de las potencias del orden" y dispuesta a encarar un fututo "desarrollo económico pacífico de efectos beneficiosos para todos sus pueblos". Por el contrario, ante lo que percibían como la "inminente caída final de la perturbadora Albión", los nacionalsocialistas señalaban que la "dictadura antialemana y belicista de Roosevelt" se preparaba para "suceder a Inglaterra no solo como potencia económica imperialista y central plutocrática sino también como enemigo del desarrollo pacífico de otros pueblos". Es en ese contexto que se inscribía, para Der Trommler, el "zarpazo final del imperialismo yanqui sobre el continente americano," mediante el establecimiento de bases militares desde Canadá hasta el Caribe. ${ }^{40}$ Detrás de ese proceso de sucesión imperial, interpretado como un acto hostil contra la "nueva Europa", Der Trommler divisaba además el intento de "invasión de la comunidad de estados iberoamericana" que fuera largamente pregonada por la "propaganda antialemana". Sin embargo, aquel no sería encabezado por el nacionalsocialismo sino por el "buen vecino," que sumaría así al "imperialismo del dólar" un "nuevo y peligroso florecimiento," implantando el "embrión de futuras convulsiones" sobre el otrora "continente de la paz". ${ }^{41}$

Así, los persistentes anuncios sobre una infiltración de las potencias del "nuevo orden europeo" no harían más que encubrir el verdadero intento norteamericano de conquistar América que se encontraría en pleno desarrollo. De este modo, para los nacionalsocialistas de la Argentina, la "campaña de mentiras y difamación contra los colonos alemanes de Misiones" de 1940 respondía a la misma lógica que "la emprendida el año anterior alrededor de la Patagonia". En su interpretación, el "reino mundial de Judá," identificado entonces con los Estados Unidos como antes lo estaba con el "bastión financiero de Londres", encabezaba una lucha "desesperada y subterránea para crear en América una base estatal que sustituyera a la Europa perdida." Para ello resultaba necesario fomentar el "odio contra todos los países y miembros de aquellas naciones que se han "librado para siempre de las cadenas de la tutela y de los déspotas judíos". ${ }^{42}$

Como en las mencionadas apreciaciones del National Zeitung, también en las páginas de Der Trommler se observa un creciente discurso

\footnotetext{
${ }^{40}$ Aunque los Estados Unidos no eran aún un país beligerante, aquella neutralidad no excluía su participación económica en el conflicto. Así, el 2 de septiembre de 1940 se firmó el acuerdo de destructores por bases (Destroyers for Bases agreement) por el cual la armada estadounidense transfería a sus pares británica y canadiense cincuenta destructores a cambio de la instalación de bases militares en Terranova, Nueva Escocia, las islas Bermudas y distintos puntos del Caribe que conformaban el imperio británico. La creación de aquellas bases fue utilizada por Der Trommler para recordar una larga historia de intervenciones militares norteamericanas y diversas violaciones a las soberanías de los estados de América Latina.

41 "Am Strom der Zeit. Prankenschlag des Yanquee-Imperialismus" (20 de septiembre de 1940), Der Trommler, pp. 12-16.

42 “Dem Dünkirchen entgegen...", pp. 19-20.
} 
antinorteamericano que en los primeros años de la década de 1940 se tornaría omnipresente entre los más fervientes partidarios del Tercer Reich en la Argentina. De hecho, en los primeros años del régimen los nacionalsocialistas no veían particularmente a los Estados Unidos como un claro enemigo ideológico. Al igual que muchos de sus contemporáneos tenían una alta valoración de diversos aspectos de la sociedad norteamericana, entre ellos su capacidad de innovación tecnológica y su elevado nivel de vida (Fischer, 2011; Imhoff, 1990). El mismo Hitler explicitó en diversas ocasiones su admiración por los Estados Unidos. La conquista del Oeste realizada a expensas de los indígenas americanos y de los mexicanos (ambos considerados como pueblos incapacitados para autogobernarse) fue tomada como un modelo a imitar en la expansión hacia el Este europeo, donde, tras el desalojo o aniquilación de los eslavos se planeaba erigir puentes más grandes que el Golden Gate y rascacielos como los neoyorkinos (Kakel, 2011; Nolan 2012). Así como el Go West norteamericano había estimulado al Lebensraum alemán, el confinamiento de los indios en "reservas" sirvió de inspiración para la conformación de los guetos judíos, una vez que fuera decidida su exclusión de la "comunidad del pueblo" (Snyder, 2015: 12). Además, los Estados Unidos eran percibidos como un modelo de higiene racial, debido a sus métodos segregacionistas y a sus restricciones migratorias que habrían protegido a una sociedad sustentada en una enérgica población de inmigrantes germánicos (Fitzgerald y Cook, 2014). Aquellas políticas eran presentadas como una contraposición positiva a las demasiado liberales leyes de la república de Weimar donde, se lamentaba Hitler, cualquiera podía transformarse en ciudadano alemán (Hartmann, Plöckinger, Töppel y Vordermayer, 2017: 1093-1095; 1115-1117). Las alabanzas a las prácticas raciales estadounidenses continuaron durante la década de 1930 y fueron tomadas por algunos juristas del tercer Reich como modelo para la elaboración de diversas legislaciones antisemitas. ${ }^{43}$

Esta imagen positiva de los Estados Unidos entre los nacionalsocialistas convivió no obstante con otra que se iría imponiendo desde el inicio de la guerra, cuando el gobierno norteamericano comenzó a suministrar armas y provisiones a los aliados: la acusación de que su sistema financiero y, por extensión cada vez en mayor medida, su gobierno estaban dominados por los judíos (Kearns Goodwin, 1995; Olson, 2014).

Los nacionalsocialistas locales incorporaron a su ubicuo discurso antisemita una muy extendida postura de diversas corrientes y tendencias ideológicas locales que denunciaban la creciente influencia política y económica estadounidense en América Latina. En esa clave interpretativa indicaban que en la segunda reunión de consulta de los ministros de relaciones exteriores americanos llevada a cabo en La Habana en julio de 1940 las "fuerzas de choque

${ }^{43}$ Sobre la influencia de las políticas raciales estadounidenses en las leyes de Núremberg ver Whitman, 2017. 
civiles estadounidenses" se habían presentado bajo la forma de "delegaciones diplomáticas" para avanzar contra la "independencia y la libertad económica de las naciones iberoamericanas". Como en el resto de los encuentros panamericanos, también aquella conferencia se habría convertido en una verdadera "batalla" alrededor de los infructuosos intentos de los Estados Unidos por convencer a los estados sud y centroamericanos de entrar en "su cártel de intereses económicos". ${ }^{44}$ Der Trommler recalcaba que en aquellas reuniones el "imperialismo yanqui" debió afrontar la "compacta y firme oposición de las repúblicas sudamericanas más fuertes y seguras de sí mismas", entre las que destacaba fundamentalmente la Argentina. ${ }^{45}$ Ante lo que consideraban un abrumador despliegue de las fuerzas estadounidenses en América Latina, los nacionalsocialistas elogiaron de manera reiterada la posición del estado argentino, definido como la "potencia líder" del subcontinente que "desde siempre" había sido el "obstáculo más fuerte a la invasión del imperialismo del dólar". ${ }^{46}$

\section{Los pueblos contra la plutocracia británica}

Durante los primeros años del conflicto bélico la publicación oficial del nacionalsocialismo de la Argentina consideraba a Inglaterra como el último "bastión de la influencia judía en Europa". Desde la isla, señalaba, los judíos habían "extendido sus tentáculos" por todo el imperio, "desde Sydney hasta ciudad del Cabo". ${ }^{47}$

Aquel dominio habría provocado no solo la explotación del pueblo británico sino también la de las oprimidas poblaciones de sus colonias. Esto se manifestaría claramente en el paradigmático caso de la "joya de la corona" donde, según indicaba Der Trommler, "el pueblo indio pasa hambre mientras que los déspotas ingleses viven en condiciones de lujo y opulencia". 48 Para dar credibilidad a sus argumentos Der Trommler recurría como cita de autoridad a la obra de William Digby, un prestigioso especialista británico insospechado de tener relación alguna con los intereses nacionalsocialistas. Esta indicaba que

\footnotetext{
44 "Am Strong der Zeit. Konferenz von Havanna" (agosto de 1940), Der Trommler, pp. 26-28.

45 Sobre la posición argentina en las conferencias panamericanas ver Morgenfeld, 2011; Rapoport, 1988; Ruiz Moreno, 1997.

46 Los denominados planes Dawes y Young, ideados para resolver el problema de las reparaciones de guerra del estado alemán, hallaron la oposición de diversos sectores que veían en ellos una creciente influencia extranjera sobre las decisiones y los recursos nacionales. Muchos grupos nacionalistas, disgustados por la dependencia del capital estadounidense, comenzaron a percibirse como víctimas de la "diplomacia del dólar," emparentándose así con los estados del Caribe (Friedman, 2012: 74-75).

47 "Juden von Sydney bis Kapstadt. Selbst Engländer klagen über die Verjudung des Empire" (20 de julio de 1940), en Der Trommler, pp. 18-19.

48 "O mein Indien! - O meine Dukaten!" (20 de agosto de 1940), Der Trommler, pp. 2-3.
} 
mientras las pérdidas en vidas humanas durante todas las guerras desatadas en el mundo entero entre 1793 y 1900 habían alcanzado la cifra de cinco millones, solamente las hambrunas sufridas por la India entre 1891 y 1900 mataron a diecinueve millones de personas (Digby, 1901).

Para Der Trommler aquellos padecimientos no obedecieron al desencadenamiento de desastres naturales ni habían sido suscitados por la falta de alimentos sino que, por el contrario, respondían al sistema de administración británica vigente en la India por más de un siglo y medio, cuyo resultado no habría sido otro que el de millones de individuos "muriendo de hambre en medio de la abundancia". ${ }^{49}$ Estos comentarios estaban acompañados por la fotografía del rozagante virrey lord Linlithgow, uno de los "amos de la India que viven con gran pompa y riqueza", cuya apariencia evidenciaba un obsceno contraste tanto con las imágenes de una víctima de un período de hambruna como con las de un trabajador textil indio, ambos igualmente desnutridos. ${ }^{50}$ Lejos de ser un caso aislado, el ejemplo indio sería el más representativo de un amplio "método de la política colonial británica", como se desprendería de la existencia de miles de mujeres coolies que eran explotadas por salarios de hambre en la colonia de Hong Kong. ${ }^{51}$

Los nacionalsocialistas recurrieron al pasado para ofrecer una clave interpretativa de los potenciales peligros en los que se encontraba el continente americano en general y la Argentina en particular. En efecto, Der Trommler describió las hazañas del general alemán Steuben en la lucha por la independencia norteamericana de Gran Bretaña, ${ }^{52}$ las que, señalaba, lejos de constituir un caso aislado, se unían a las de "otros líderes y otros miles de soldados alemanes desconocidos que valientes y fieles, lucharon y murieron por la libertad de América".$^{53}$ Este relato resaltaba al mismo tiempo la decidida labor y el compromiso con la emancipación continental tanto de ilustres como de anónimos alemanes que combatieron denodadamente contra los ingleses. No obstante, el contraste más evidente entre aquel heroico proceder que habría contribuido al engrandecimiento americano y las históricamente inescrupulosas acciones de los anglosajones se veía reflejada en un caso que por entonces estaba transformándose en un preciado símbolo del nacionalismo argentino: las Malvinas.

\footnotetext{
${ }^{49}$ Dr. A (20 de agosto de 1940). “Indien hungert.," Der Trommler, p. 3.

50 Der Trommler (20 agosto de 1940), pp. 32-33.

51 “Weibliche Kulis in Hong Kong” (agosto de 1940), Der Trommler, p. 32.

52 Friedrich Wilhelm Ludolf Gerhard Augustin von Steuben, también conocido como Barón von Steuben (Magdeburgo, 17 de septiembre de 1730- Nueva York, 28 de noviembre de 1794), fue un oficial prusiano que combatió junto a George Washington durante la guerra de la independencia estadounidense.

53 "Steubens Grosstaat für Amerikas Freiheit" (5 de octubre de 1940), Der Trommler, pp. 20-22.
} 
Desde la segunda mitad de la década de 1930 distintos sectores del arco político comenzaron a tomar el caso de las islas Malvinas como un símbolo de reivindicación nacional que delataba no solo la presencia británica en la Argentina sino además la subordinación de los gobiernos de turno a los intereses foráneos (Halperin Donghi, 2003: 55-98). Este análisis se enlazaba a la creciente importancia de la temática del imperialismo como clave explicativa de las penurias económicas y políticas de la experiencia argentina. ${ }^{54} \mathrm{Si}$ bien estas interpretaciones han sido con razón asociadas al nacionalismo de los "nacionalistas" o al movimiento revisionista, formaron parte de un clima mucho más amplio que por entonces se encontraba en pleno desarrollo y abarcaba a un conjunto de personas que excedía a aquellas manifestaciones. Un claro ejemplo de aquel amplio consenso fue Alfredo Palacios, activo militante del antifascismo local y de estrechas relaciones con muchos alemanes antinazis, quien había presentado en 1934 un proyecto de ley para concientizar a los argentinos de que aquellas islas habían sido usurpadas ilegalmente por los británicos mediante el uso de la fuerza (Lorenz, 2014: 123). Por su parte, la revista Clarinada (algunos de cuyos artículos tuvieron esporádicas apariciones en Der Trommler) elogiaba a la organización Alianza de la Juventud Nacionalista por repudiar que en "un rincón de la patria robado por el imperialismo británico" no se izara la "bandera blanca y azul en el aniversario de nuestro glorioso 25 de mayo". Clarinada felicitó a aquella "ferviente juventud argentina" porque en el escenario del teatro Marconi había estampado su "enérgica consigna: Falkland Islands, no; Islas Malvinas, sí". ${ }^{55}$

En aquel contexto, un artículo de Der Trommler titulado "Piratería y saqueo" narraba la historia de aquellas islas desde su descubrimiento hasta 1820, cuando "la joven República Argentina se transformó en su legítima poseedora". Desde entonces, proseguía, gracias a la "genial perspicacia" de su gobernador, el hamburgués Luis Vernet, comenzó la colonización y el desarrollo sistemático de la zona que, mediante el aprovechamiento integral de sus riquezas naturales, pudo colocar sus productos en el mercado mundial. Aquella prosperidad atrajo "una vez más la codicia de los ingleses," quienes, apelando a espurias maniobras que incluyeron el engaño y el soborno, consumaron finalmente en 1833 "el inescrupuloso robo" de las islas. Así fue como los británicos, "practicantes experimentados del saqueo", permanecieron en posesión de las Malvinas, erosionando el "natural orgullo nacional de los argentinos" y desoyendo las constantes protestas formales realizadas por su gobierno. No obstante, la publicación nacionalsocialista finalizaba su reseña

\footnotetext{
${ }^{54}$ Sobre el antiimperialismo ver Cattaruzza, 2007: 176 y ss; Goebel, 2013: 11-86; Romero, 2018.

55 "Actividades nacionalistas" (junio de 1938), Clarinada, p. 9. Dirigida por Carlos M. Silveyra, Clarinada fue publicada entre 1937 y 1945. Se caracterizó por un muy virulento anticomunismo y antisemitismo. Aunque estuvo subsidiada por la embajada alemana, su identificación con el catolicismo la diferenciaba del nacionalsocialismo (Lvovich, 2003: 301 y ss.; Newton, 1992: 122124). Sobre la Alianza de la Juventud Nacionalista ver Besoky, 2014.
} 
histórica con un mensaje amenazante y esperanzador: "llegará el día en el que los pueblos saldarán sus cuentas con la plutocracia británica". ${ }^{56}$

\section{Escenario transformado}

A mediados de 1941 se conformó en la Cámara de Diputados de la Nación la Comisión Investigadora de Actividades Antiargentinas que, integrada por diputados de distintos partidos, se propuso investigar organizaciones e individuos con "ideologías y métodos contrarios a las instituciones republicanas y a nuestra soberanía". ${ }^{57}$ La comisión elaboró diversos informes que revelaron la persistencia de distintas organizaciones nacionalsocialistas que, violando la prohibición impuesta por el decreto de mayo de 1939, continuarían desempeñándose de manera encubierta como "células antiargentinas en acción". ${ }^{8}$ Como había sucedido con las iniciativas legislativas de Dickmann y Damonte Taborda de los años 1938 y 1939, también los miembros de esta comisión tomaron gran parte de su material de las denuncias llevadas a cabo por antinazis germanoparlantes, con quienes, en algunos casos, compartieron una activa militancia antifascista y, en otros, sostuvieron relaciones personales de diversa índole (Friedmann, 2010: 106).

Los principales periódicos de alcance nacional le dedicaron un importante espacio a la labor realizada por esta institución parlamentaria. Seguramente la profesión periodística y los contactos sostenidos por la mayor parte de sus miembros con distintos medios de información favorecieron la enorme repercusión pública alcanzada por sus investigaciones. Aquel alcance respondía además al marcado cambio en el contexto internacional. En este sentido, aunque los presuntos intentos de violación a la soberanía argentina por parte de un gobierno extranjero habían encontrado un rechazo unánime en distintos medios, entre los grandes periódicos de tirada nacional, solo Crítica había condenado fuertemente al régimen de Hitler desde su llegada al poder. Este escenario fue transformándose desde la declaración de la guerra y la invasión de las tropas alemanas a París, hasta que finalmente con la entrada de

\footnotetext{
56 "Piratentum und Länderraub. Die Malvinen (Falklandinseln)" (5 de octubre de 1940), en Der Trommler, pp. 24-26.

57 En un inicio estuvo presidida por Raúl Damonte Taborda e integrada además por los diputados Juan Antonio Solari, Adolfo Lanús, Fernando de Prat Gay, Silvano Santander, José Aguirre Cámara y Guillermo O'Reilly. Los radicales Damonte Taborda y Santander dimitieron en julio de 1942 y Solari pasó a ocupar la presidencia (Friedmann, 2010: 100-104)

${ }^{58}$ Congreso nacional, Cámara de Diputados, Diario de Sesiones, informe número 1, 29 de agosto de 1941 (publicado el 5 de septiembre de 1941, pp. 67-104); informe número 2, 5 de septiembre de 1941, pp. 105-150; informe número 3, 17 de septiembre de 1941, pp. 643-687; informe número 4, 30 de septiembre de 1941, pp. 824- 950; e informe número 5, 28 de noviembre de 1941 (publicado el 30 de noviembre de 1941, pp. 1-270).
} 
los Estados Unidos en el conflicto se generalizó en el grueso de la prensa la adhesión abierta a la causa aliada (Tato y Romero, 2002).

En ese clima de condena general al gobierno alemán los nacionalsocialistas moderaron su discurso impulsados por la necesidad de mantener un perfil más bajo ante una situación de creciente exposición. De esta forma, en las páginas de sus publicaciones se atenuaron las críticas abiertas contra ciudadanos argentinos, tan frecuentes hasta entonces, por ejemplo, contra quienes habían impulsado las investigaciones sobre la "infiltración nazi". En el mismo sentido, la reprobación al proceder de los gobiernos estadounidense o británico dejó de concentrarse en sus supuestas injerencias en el terreno local para apuntar fundamentalmente a sus discrepancias ideológicas. Así, por ejemplo, Der Trommler caracterizaba a Churchill como "enemigo de los trabajadores ingleses" porque habría eliminado todos los acuerdos salariales hasta entonces vigentes en el Reino Unido. ${ }^{59}$

Cabe destacar que, a diferencia del periódico publicado en idioma alemán Deutsche La Plata Zeitung o de la revista Clarinada, editada en castellano, cuya adhesión al gobierno del Reich descansaba fundamentalmente en su ferviente anticomunismo, el discurso de los nacionalsocialistas locales realizaba un fuerte énfasis en la igualdad y la nivelación social (ambas, desde luego, para aquellos dignos de conformar la "comunidad popular"). Además, entre finales de la década de 1930 y principios de la siguiente, su publicación oficial no tuvo manifestaciones abiertamente anticomunistas. Es muy probable que aquella ausencia respondiera primordialmente al ambiente generado tras el pacto de no agresión germano-soviético firmado el 23 de agosto de 1939 en Moscú por los ministros de Asuntos Exteriores Joachim von Ribbentrop y Vyacheslav Molotov. ${ }^{60}$ "Un año de amistad ruso-alemana" fue el título elegido por Der Trommler con motivo del primer aniversario del tratado ruso-alemán, al que defendía porque incluso antes del inicio de la guerra habría abortado el intento de un nuevo Hungerblockade, término que designaba al bloqueo de alimentos establecido en Alemania por parte de la armada británica durante el anterior conflicto armado. ${ }^{61}$ Der Trommler condenaba los incesantes intentos de la "propaganda antialemana" de perturbar el equilibrio alcanzado por aquel acuerdo y celebraba la firmeza de ambos gobiernos, gracias a la cual aquella harmonía no se habría visto comprometida por "enemistades políticamente injustificadas." 62

\footnotetext{
59 “Churchill-Feind der englischen Arbeiter" (5 de mayo de 1941), Der Trommler, p. 13.

${ }^{60}$ Sobre el pacto de no agresión ver Koch, 2015.

61 Con el fin de exacerbar los sentimientos antibritánicos, la propaganda nacionalsocialista recurrió a la muy fuerte creencia popular de que los ingleses habían utilizado el hambre como arma contra civiles vulnerables durante la Primea Guerra.

62 "Ein Jahr deutsch-russische Freundschaft" (20 de septiembre de 1940), Der Trommler, p. 15.
} 
Esta última aseveración no expresaba solamente a una cuestión instrumental motivada por la vigencia del pacto entre la Unión Soviética y el Reich. Por el contrario, los nacionalsocialistas de la Argentina creían compartir ciertas sensibilidades políticas y sociales con algunos germanoparlantes que simpatizaban con el comunismo, a quienes consideraban que podían incorporar a sus propias filas. Ya en octubre de 1940 Der Trommler había señalado que Churchill y Roosevelt se encontraban unidos en el temor al "socialismo en ascenso" que liberaría "a las masas del yugo de una Weltanschauung de explotación plutocrática". ${ }^{63}$ En sus páginas resultaron frecuentes los informes que resaltaban las diversas políticas sociales inclusivas del Tercer Reich que habrían abarcado a un vasto conjunto de la población alemana hasta entonces relegado. Esta promoción de la nivelación social no solo formaba parte de una estrategia que buscaba legitimar al régimen entre aquellos alemanes que no estaban excluidos de la "comunidad del pueblo". Más bien estaba profundamente arraigada en las convicciones ideológicas de muchos nacionalsocialistas, quienes se declaraban representantes del auténtico socialismo alemán, entendido como la solidaridad de todos los miembros de una Volksgemeinschaft teóricamente unida y homogénea. ${ }^{64}$ Como indicara un militante nacionalsocialista, la rama argentina del partido se adecuaba mejor que otras al lema de la escuela de formación de líderes del partido en Altona: "nuestra bandera porta la cruz gamada, pero ella es y seguirá siendo roja" (Volberg, 1981: 30).

De todos modos, y más allá de que durante la vigencia del pacto ruso alemán moderaron sus ataques contra el régimen de Stalin al tiempo que incrementaron sus cuestionamientos contra el imperialismo inglés y norteamericano, con la entrada soviética en la guerra las publicaciones pertenecientes al nacionalsocialismo local retomaron con mayor vehemencia sus críticas al comunismo. Der Deutsche in Argentinien indicaba que bajo el liderazgo de Hitler los "jóvenes pueblos europeos" habían conseguido durante 1941 una impactante serie de victorias que abrían gigantescos pasos en el "camino hacia un nuevo orden". Sin embargo, recién hacia mediados de aquel año se habría producido el "mayor evento de la historia mundial". Así era definido el avance de las tropas alemanes hacia el territorio soviético, interpretado como un acto de prevención y una "iniciativa responsable ante el peligro de aniquilación de Alemania, Europa y el mundo entero". A partir de entonces diversas naciones habrían seguido al Reich, "transformando a la guerra contra la Unión Soviética en una "cruzada de Europa contra el bolchevismo". ${ }^{65}$ Ya hacia mediados de 1943, cuando la Segunda Guerra

\footnotetext{
63 "Dem Dünkirchen entgegen. Schattenspiele der Deutschlandhetze" (5 de octubre de 1940), Der Trommler, pp. 19-20.

${ }^{64}$ Sobre el concepto de Volksgemeinschaft (comunidad del pueblo) ver Kershaw, 2011.

65 "Zur Jahreswende" (enero de 1942), Der Deutsche in Argentinien, p. 1.
} 
Mundial había tomado un giro decisivo que, incluso entre los nacionalsocialistas más optimistas dejaba vislumbrar un resultado desfavorable para la aventura bélica alemana, Der Deutsche in Argentinien continuaba impulsando la lucha contra las "internacionales del capitalismo" con epicentro en Nueva York y Londres (por entonces nuevamente vigente, tras la sombría verificación de su invulnerabilidad). Sin embargo, al mismo nivel que el judaísmo, al que veía corporizado en "las altas finanzas," aparecía ahora el comunismo como el "enemigo principal". ${ }^{66}$

\section{Consideraciones finales}

Los primeros informes referidos a una "infiltración nazi" en la Argentina se originaron en la actividad propagandística desempeñada por militantes antihitleristas de distintas procedencias ideológicas que difundieron, entre los germanoparlantes locales, tanto noticias sobre las atrocidades cometidas en Europa por el nacionalsocialismo como su exitosa expansión en distintas instituciones de la colectividad alemana. Las revelaciones sobre las supuestas actividades ilegales de una "red parda" se realizaron en un principio en publicaciones de idioma alemán y tuvieron luego una fuerte repercusión en los medios de prensa nacionales e internacionales. Aquellas denuncias sobre una "quinta columna" preparada para favorecer un eventual asalto al continente sudamericano transformaron a los diversos grupos de alemanes opositores a Hitler en el ala germanoparlante de un variopinto movimiento antifascista local. ${ }^{67}$

Motivados por un auténtico convencimiento acerca de un peligro real de "subversión nazi" o producto de tergiversaciones debidas a la propaganda bélica, los temores suscitados ante la posible creación de "los Sudetes de América Latina" encontraron una notable recepción que vista en retrospectiva puede resultar un tanto extravagante. La propagada creencia en un nacionalsocialismo casi omnipresente resultó en un inicio funcional tanto a los intereses de sus adherentes como a los de sus opositores. En ambos casos, el sobredimensionamiento de las fuerzas del tercer Reich -ya fuera leído en clave de éxito o de peligro- proclamado con fines propagandísticos contribuyó también, conscientemente o no, a reforzar las respectivas identidades de nacionalsocialistas y antinazis. Sin embargo, terminó siendo contraproducente tanto para los primeros, quienes vieron limitadas seriamente sus capacidades de acción en el país, como para sus opositores, que compartieron con el conjunto de los germano-argentinos el mismo sentimiento de hostigamiento general hacia los alemanes.

\footnotetext{
66 "Europa und der Krieg" (julio de 1943), Der Deutsche in Argentinien, p. 1.

67 Sobre el antifascismo argentino ver Bisso, 2007; Pasolini, 2013; Zanca, 2013.
} 
La sobreestimación del peligro que suponían las "minorías alemanas" y las organizaciones nacionalsocialistas para la estabilidad política argentina en particular y de los países latinoamericanos en general dejaba al descubierto la percepción de una limitada capacidad de defensa de aquellos estados. Esta situación provocó tanto en los medios como en la opinión pública norteamericana un resurgimiento de algunos aspectos de la denominada "doctrina Monroe" y dio un nuevo impulso a la idea del "destino manifiesto" (Sexton, 2011; Horsman, 1981). Así, se reflotaron viejas concepciones que hacían hincapié en la imposibilidad de los latinoamericanos de autogobernarse libremente y en la correspondiente misión civilizadora de los Estados Unidos en clave de expansión de la democracia y la libertad. De hecho, una parte importante de las tensiones y crisis diplomáticas suscitadas entre los gobiernos argentino y estadounidense tras finalizar la guerra se originó en la continuidad de la imagen norteamericana de un desafío nacionalsocialista que habría allanado el terreno para la creación de un "cuarto Reich" en la región. ${ }^{68}$

En el escenario político local las reacciones ante la amenaza de una infiltración nacionalsocialista evidenciaron un creciente nacionalismo de índole exclusivista que percibía a la heterogeneidad cultural como un serio desafío a la integridad territorial argentina mediante la constitución de entidades autónomas dentro del estado nacional. Un claro ejemplo de ello fue la postura adoptada por los integrantes de la Comisión de Actividades Antiargentinas cuando recomendaron la supresión de las escuelas idiomáticas porque estaban "manifiestamente destinadas a fomentar el perfeccionamiento de idiomas extranjeros" y encargaron la urgente realización, "en las regiones más apartadas de nuestra patria", de un plan sistemático de construcción de escuelas públicas para defender el "patrimonio moral, intelectual y físico de la argentinidad". ${ }^{69}$ Aquel reclamo de "argentinización" de los territorios, con la consecuente petición de aumentar la presencia estatal frente al peligro del denunciado avance del nacionalismo entre las colectividades extranjeras radicadas en aquellos distritos, era una de las maneras en que en la época se manifestaba el recurrente temor argentino a las potenciales consecuencias negativas de contar con una población escasa para su vasta geografía (Romero, 2004).

Este clima fue apreciado por los nacionalsocialistas radicados en el país, como se observa en su indignada reacción ante las "inauditas vejaciones y tormentos" a las que habrían sido expuestos los "antiguos colonos de Misiones." Tras repudiar aquellos suplicios provocados por la "incitación al odio antigermana", reivindicaban además el "trabajo de esos pioneros alemanes" que "sin apoyo del estado entablaron y condujeron exitosamente la

\footnotetext{
${ }^{68}$ Sobre el papel desempeñado por los servicios de inteligencia de Gran Bretaña y los Estados Unidos en la construcción del mito de un "cuarto Reich" ver Newton, 1992: 343-359.

${ }^{69}$ Congreso Nacional, Cámara de Diputados, Diario de Sesiones, 30 de septiembre de 1941, pp. 826-861.
} 
lucha contra la selva", región que gracias a su incansable labor -subrayaban con énfasis- no "sólo había logrado desarrollarse económicamente, sino también incorporarse al país". ${ }^{70}$ En aquel ambiente signado por un renovado nacionalismo y una creciente sensación de vulnerabilidad, los partidarios de Hitler denunciaron que las revelaciones sobre una supuesta "invasión nazi" encubrían lo que percibían como la verdadera amenaza de la "infiltración judía" (último propósito de la manipulación de los aliados y sobre todo de los Estados Unidos) y el "imperialismo anglo-yanqui".

Aunque los nacionalsocialistas tomaron el discurso del antiimperialismo por entonces en boga, denunciando por igual a los explotadores ingleses y norteamericanos, no reprobaron sin embargo el proceder de sus representantes locales, algo frecuente en aquel entonces. La única excepción la constituían desde luego los judíos, a quienes no reconocían como argentinos de acuerdo con su concepción de la Volksgemeinschaft, comunidad en la que arraigaban por igual nación, pueblo y raza. Por el contrario, elogiaron insistentemente la posición adoptada en las conferencias panamericanas por las autoridades argentinas, proclamando que su férrea oposición a los intentos de avanzada de la nueva potencia norteamericana sobre el continente habría sostenido una valiente política exterior de autodeterminación a pesar de las crecientes amenazas de represalias por parte de una belicista "plutocracia judía" de Washington.

Las acciones y los discursos nacionalsocialistas se dirigían a un grupo extremadamente variado de personas que potencialmente podían conformar una comunidad popular pretendidamente homogénea. En aquel conjunto se encontraban tanto aquellos que habían nacido en el Reich como quienes habían arribado al país desde diversas regiones de habla alemana y otros que, oriundos de la Argentina, tenían distintos grados de contacto con la vida cultural, política o económica germanoparlante. Todos ellos, como el resto de la población local, compartían aquel clima en el cual la lectura antiimperialista constituía una clave de interpretación cada vez más frecuente de la experiencia argentina.

La condena al imperialismo "anglo-yanqui" y la apología del estado argentino respondían a convicciones ideológicas enraizadas en distintos grados en los simpatizantes del nacionalsocialismo a partir de sus experiencias europeas $\mathrm{o}$ argentinas. Pero además se combinaban con argumentos estratégicos utilizados en un momento en el que aquellos se sentían apremiados por lo que percibían como un omnipresente clima antialemán ante el cual consideraban necesario expresar su lealtad hacia el estado que los cobijaba con la esperanza de continuar con sus actividades habituales. En este mismo sentido la incorporación del caso de las Malvinas al discurso nacionalsocialista puede ser interpretada a la vez como un alegato esgrimido para ganarse la

70 Dr. A, “Deutschenhetze wieder aktuell” (5 de octubre de 1940), Der Trommler, p. 32. 
simpatía de los argentinos y como una creencia arraigada en los partidarios locales del tercer Reich.

Buenos Aires, julio de 2019.

\section{Bibliografía citada}

Bauer, Kurt (2017). Die dunklen Jahre: Politik und Alltag im nationalsozialistischen Österreich 1938 bis 1945, Fráncfort del Meno: Fischer.

Besoky, Juan Luis (2014). "El nacionalismo populista de derecha: La Alianza Libertadora Nacionalista 1937-1975”, en Mediações, vol. 19, núm. 1, pp. 61-83.

Bisso, Andrés (2007). El antifascismo argentino, Buenos Aires: CeDInCI, BuenosLibros.

Cattaruzza, Alejandro (2007). Los usos del pasado. La historia y la política argentinas en discusión, 1910-1945, Buenos Aires: Sudamericana.

Digby, William (1901). "Prosperous" British India: A Revelation from Official Records, Londres: T. Fisher Unwin.

Efron, David (1939). "Latin America and the Fascist 'Holy Alliance', en Annals of the American Academy of Political and Social Science, Tomo 204, pp. 17-25.

Fischer, Klaus (2011). Hitler and America, Filadelfia: University of Pennsyvania Press.

Fitzgerald, David Scott y Cook-Martin, David (2014). Culling the Masses. The Democratic Origins of Racist Immigration Policy in the Americas, Cambridge: Harvard University Press.

Friedman, Max Paul (2003). Nazis and Good Neighbors: The United States Campaign against the Germans of Latin America in World War II, Nueva York: Cambridge University Press.

Friedman, Max Paul (2012). Rethinking Anti-Americanism: The History of an Exceptional Concept in American Foreign Relations, Nueva York: Cambridge University Press.

Friedmann, Germán (2009). “La política guerrera. La investigación de las Actividades Antiargentinas", en Bertoni, Liliana y De Privitellio, Luciano (comp.) Conflictos en democracia. La política en la Argentina, 1852-1943, Buenos Aires: Siglo XXI, pp. 191-212.

Friedmann, Germán (2010). Alemanes antinazis en la Argentina, Buenos Aires: Siglo XXI. 
Friedmann, Germán (2015). “El Frente Negro en la Argentina durante la década de 1930", en Iberoamericana. América Latina-España-Portugal, Madrid-Fráncfort del Meno, Nueva época, núm. 57, pp. 39-57.

Goebel, Michael (2013). La Argentina partida. Nacionalismos y políticas de la historia, Buenos Aires: Prometeo.

Groth, Hendrik (1996). Das Argentinische Tageblatt. Sprachrohr der demokratischen Deutschen und der deutsch-jüdischen Emigration, Hamburgo: LIT Verlag.

Halperin Donghi, Tulio (2003). La Argentina y la tormenta del mundo. Ideas e ideologías entre 1930 y 1945, Buenos Aires: Siglo XXI.

Hartmann, Christian; Plöckinger, Othmar; Töppel, Roman y Vordermayer, Thomas (eds.) (2017). Hitler, Mein Kampf: Eine kritische Edition, tomo 2, Múnich: Institut für Zeitgeschichte München

Horsman, Reginald (1981). Race and Manifest Destiny. The Origins of American Racial Anglo Saxonism, Cambridge-Londres: Harvard University Press.

Imhoff, Gérard (1990). "Der Amerikanismus der zwanziger Jahre oder die Versuchung einer alternative Weltbildes", en Revue d'Allemagne et des Pays de langue allemande, Société d'Etudes Allemandes, Estrasburgo, 22/3, pp. 427-437.

Ismar, Georg (2006). Der Pressekrieg. Argentinisches Tageblatt und Deutsche La Plata Zeitung 1933-1945, Berlín: Wvb.

Kakel, Carrol (2011). The American West and the Nazi East: a comparative and Interpretative Perspective, Nueva York: Palgrave Macmillan.

Kearns Goodwin, Doris (1995). No Ordinary Time: Franklin and Eleanor Roosevelt: The Home Front in World War II, Nueva York: Simon \& Schuster.

Kershaw, Ian (2011). "Volksgemeinschaft. Potenzial und Grenzen eines neuen Forschungskonzepts", en Vierteljahrshefte für Zeitgeschichte, Múnich, Oldenbourg, pp. 1 -17.

Koch, Christoph (comp.) (2015). Gab es einen Stalin-Hitler-Pakt?: Charakter, Bedeutung und Deutung des deutsch-sowjetischen Nichtangriffsvertrages vom 23. August 1939, Fráncfort del Meno: Peter Lang GmbH.

Laberenz, Lennart (2006). Von Kaiser zum Führer. Deutschsprachige Nationalismusdiskurse in Buenos Aires 1918-1933, Tesis de maestría, Berlín: Universidad de Berlín.

Lorenz, Federico (2014). Todo lo que necesitás saber sobre Malvinas, Buenos Aires: Paidós.

Lübke, Uwe (2008). “Angst vor dem 'Vierten Reich': Argentinien in der Bedrohungswahrnehmung der USA", en Meding, Holger e Ismar, Georg (comp.) Argentinien und das Dritte Reich. Mediale und reale Präsenz, Ideologietransfer, Folgewirkungen, Berlín: Wvb, pp. 101-120. 
Lütge, Wilhelm (et al.) (1981). Deutsche in Argentinien 1520-1980, Buenos Aires: Alemann.

Lvovich, Daniel (2003). Nacionalismo y antisemitismo en la Argentina, Buenos Aires: Vergara.

Morgenfeld, Leandro (2011). Vecinos en conflicto. Argentina y Estados Unidos en las Conferencias Panamericanas (1880-1945), Buenos Aires: Peña Lillo.

Newton, Ronald (1992). The "Nazi Menace" in Argentina, 1931-1947, Stanford: Stanford University Press, Stanford.

Nolan, Mary (2012). The Transatlantic Century Europe and America, 1890-2010, Nueva York: Cambridge University Press.

Olson, Lynne (2014). Those Angry Days: Roosevelt, Lindbergh, and America's Fight Over World War II, 1939-1941, Nueva York: Random House.

Pasolini, Ricardo (2013). Los marxistas liberales. Antifascismo y cultura comunista en la Argentina del siglo XX, Buenos Aires: Sudamericana.

Rapoport, Mario (1988). ¿Aliados o neutrales? La Argentina frente a la Segunda Guerra Mundial, Buenos Aires: EUDEBA.

Romero, Juan Manuel (2018). “FORJA y el antiimperialismo en la Argentina de los años treinta", Foros de Historia Política núm. 6, Mar del Plata: Programa Interuniversitario de Historia Política. Disponible en: http: //historiapolitica.com/foros/intelectuales-antiimperialismo-y-politica-enamerica-latina-1898-1939/, ISSN 2469-0740.

Romero, Luis Alberto (coord.) (2004). La Argentina en la escuela. La idea de nación en los textos escolares, Buenos Aires: Siglo XXI.

Rout, Leslie y Bratzel, John (1984). "Heinrich Jürges and the Cult of Disinformation", en International History Review, vol. 6, núm. 4, pp. 611-623.

Ruiz Moreno, Isidoro (1997). La neutralidad argentina en la Segunda Guerra Mundial, Buenos Aires: Emecé

Schmitz-Berning, Cornelia (2007). Vokabular des Nationalsozialismus, Berlín: Walter de Gruyter.

Schoepp, Sebastian (1996). Das Argentinische Tageblatt 1933 bis 1945. Ein Forum antinationalisozialistischen Emigranten, Berlín: Wissenschaftlicher Verlag.

Senkman, Leonardo (1991). Argentina, la segunda guerra mundial y los refugiados indeseables. 1933-1945, Buenos Aires: GEL.

Sexton, Jay (2011). The Monroe Doctrine: Empire and Nation in 19th-Century America, Nueva York: Hill \& Wang. 
Seyferth, Giralda (1999). “Os imigrantes e a campanha de nacionalização do Estado Novo", en Pandolfi, Dulce (comp.) Repensando O Estado Novo, Río de Janeiro: Fundação Getulio Vargas, pp. 199-228.

Snyder, Timothy (2015). Black Earth: The Holocaust as History and Warning, Nueva York: Tim Duggan Books.

Tato, María Inés y Romero, Luis Alberto (2002). “La prensa periódica argentina y el régimen nazi", en Klich, Ignacio (comp.) Sobre nazis y nazismo en la cultura argentina, Gaithersburg: Hispamérica.

Volberg, Heinrich (1981). Auslandsdeutschtum und Drittes Reich: der Fall Argentinien, Böhlau, Colonia-Viena.

Whitman, James (2017). Hitler's American Model. The United States and the Making of Nazi Race Law, New Jersey: Princeton University Press.

Zanca, José (2013). Cristianos antifascistas. Conflictos en la cultura católica argentina, Buenos Aires: Siglo XXI. 